\title{
Representación Política Sustantiva En México: Una Mirada Desde La Subjetividad Política De Las Minorías Indígenas ${ }^{3}$
}

\author{
Dr. Raúl Rocha Romero \\ Lic. Cintia Flores Hernández \\ Facultad de Estudios Superiores Zaragoza, UNAM
}

doi: 10.19044/esj.2017.v13n16p192 URL:http://dx.doi.org/10.19044/esj.2017.v13n16p192

\begin{abstract}
Within the framework of a larger study on the subjective, institutional and cultural factors that influence the substantive political representation of indigenous minorities in Mexico, the theoretical-methodological and empirical approach is presented in relation to the political subjectivity of indigenous peoples of the Mexican states of Oaxaca and Chiapas, with respect to the political representation of which they are subject by their federal deputies. A total of 46 interviews were conducted with Indians from Oaxaca and Chiapas in their respective places of residence. The results show a political subjectivity marked by descriptive, negative and valorative opinions. Indigenous people express not only the neglect they have been subjected to by representatives, but also the fact that national policy is totally alien to them. For the Indians of Mexico this means that they have not yet incorporated as citizens of the republic.
\end{abstract}

Keywords: Substantive political representation, political subjectivity, Indians

\section{Resumen}

En el marco de un estudio más amplio acerca de los factores subjetivos, institucionales y culturales que influyen en la representación política sustantiva de las minorías indígenas en México, se presenta la aproximación teórico-metodológica y empírica en relación a la subjetividad política de indígenas de los estados mexicanos de Oaxaca y Chiapas, respecto de la representación política de la que son objeto por parte de sus diputados federales. Se realizaron 46 entrevistas a indios de Oaxaca y de

\footnotetext{
${ }^{3}$ Este texto es resultado de una investigación más amplia que se está realizando gracias al
} apoyo del Programa UNAM-DGAPA-PAPIIT IN305015. 
Chiapas en sus respectivos lugares de residencia. Los resultados muestran una subjetividad política marcada más por opiniones descriptivas, negativas y valorativas. Los indígenas expresan no sólo el olvido del que han sido objeto por parte de los representantes, sino, por ello, también el hecho de que la política nacional les es totalmente ajena. Para los indios de México esto significa que aún no s eles ha incorporado como ciudadanos de la república.

Palabras clave: Representación política sustantiva, subjetividad política, indios

\section{Introduction}

Este texto forma parte de la investigación interdisciplinaria Factores Subjetivos, Institucionales y Culturales que influyen en la Representación Política Sustantiva de las Minorías Indígenas en México. En otro lugar (Rocha, 2016), se definieron las diferentes perspectivas teóricas a tomar en cuenta para realizar un abordaje integral de la representación política, mismas que se están desarrollando con la intención de articularlas. Dichas perspectivas son las siguientes: 1) representación política, 2) representación política sustantiva, pluralismo cultural y minorías indígenas, 3) Instituciones y representación política sustantiva de la diversidad; 4) subjetividad política y representación sustantiva de minorías indígenas; y 5) cultura política y representación sustantiva de minorías indígenas. Por ello, aquí se presenta únicamente la aproximación teórico-metodológica y empírica en relación a la dimensión subjetiva de indígenas de los estados de Oaxaca y Chiapas, respecto de la representación política de la que son objeto por parte de sus diputados federales. Por razones de espacio, no se incorporan los resultados con los que ya se cuenta respecto de ciudadanos y diputados federales mexicanos y, en este sentido, tampoco se incluye el desarrollo teórico respecto de la dimensión institucional y cultural en relación a la representación política.

La premisa de la que se parte considera la subjetividad política de las personas, es decir, el contenido político de los procesos cognitivos y emocionales, como una vía para acercarse a la forma como los representantes políticos actúan ante sus representados. De esta manera, se concibe a la representación política como actuación y, en cuanto tal, como responsividad (responsiveness), reciprocidad y empatía del representante frente a sus representados.

A partir de la evidente desvinculación política, ideológica y programática entre representantes y representados, es que algunos autores hablan de la crisis de la representación política (Gargarella, 1997; Abal, 2004). Incluso, el problema de la representación política se agudiza si consideramos las tensiones emergentes entre los principios normativos de la 
democracia representativa y la existencia al interior de las sociedades actuales de diversos pluralismos. Así, para el caso que nos ocupa, el reto es cómo articular la igualdad ciudadana de los individuos con la pluralidad social y cultural realmente existentes. Al respecto afirmamos que la diversidad y diferencia demandan de un trato político diferenciado con el objeto de compensar y revertir las desigualdades sociales, económicas y políticas.

La representación política

Para decirlo de manera llana: representación política significa que el gobierno o la producción de legislación y políticas públicas no son facultades de los ciudadanos, sino de los gobernantes y legisladores autorizados por los propios ciudadanos a través de las elecciones.

Existen dos dimensiones fundamentales de la representación política: representación descriptiva y representación sustantiva. La primera implica el diseño institucional de las legislaturas. La segunda, por su parte, alude a aquello que lo hace representativo en virtud de que la representación es también una actividad, una actuación realizada por parte de los representantes. En este punto emergen las controversias entre mandato e independencia de los representantes frente a sus representados (Pitkin, 1985). Para esta autora, dichas controversias se resuelven si se asume que representación significa actuar de un modo responsivo (sensible) bajo los intereses de los representados.

Por otro lado, en las democracias liberales existen mecanismos institucionales para asegurar una mayor vinculación política entre el que delega la autoridad y el que la ejerce. Estos son derivados básicamente de las nociones de mandato, accountability y responsividad. Así, Przeworsky (1998) y Manin, Przeworsky y Stokes (1999) distinguen dos modelos: a) la representación como mandato, y b) la representación como responsabilidad y control (accountability).

Específicamente, desde la ciencia política se construye la representación política a través de los procesos de delegación y rendición de cuentas. El objetivo consiste en crear instituciones que motiven al agente (gobernantes, representantes o políticos) a actuar a favor de los intereses del principal (gobernados, representados o ciudadanos). Precisamente para ello se diseñan mecanismos de rendición de cuentas (accountability) que introduzcan incentivos positivos y negativos para el agente, así como la posibilidad de monitorear la actuación del agente por parte del principal. En esta perspectiva, para O’Donnell (2000), la rendición de cuentas incluye dos dimensiones: la horizontal y la vertical.

Como se observa, los mecanismos institucionales de la representación política pretenden establecer un vínculo más estrecho entre representantes y representados, sin embargo, para los ciudadanos las perspectivas son 
limitadas en el sentido de que la representación se agota en el proceso de autorización y delegación del ejercicio de la autoridad otorgado en las elecciones. Pero respecto de los gobernantes y los representantes, y a pesar de los mecanismos institucionales señalados, no existen criterios políticos claros porque actuar a favor de los intereses del público es una interpretación demasiado vaga que se resuelve según las circunstancias políticas (Rocha, 2005a).

De lo anterior, se desprende la necesidad de colocar en el centro del análisis la representación política sustantiva enfocada desde el ángulo de la responsividad (Lindaman, 2011). El término inglés responsiveness es entendido generalmente como sensibilidad, pero otros autores utilizan la acepción de reciprocidad. Así, para Morlino (2007: 39) la reciprocidad "es la capacidad de satisfacer los intereses de los gobernados al ejecutar las políticas que responden a sus demandas”.

Estos argumentos remiten directamente al sentido de actuación que se considera aquí al respecto de la representación política. Eulan y Karps (1977) han mostrado que la reciprocidad permite observar a la representación política como acción. Estos mismos autores especifican que la reciprocidad así concebida incluye cuatro componentes: las políticas públicas colocadas en el centro de los procesos políticos; los servicios que son garantizados a los individuos y grupos por el propio gobierno; la distribución de bienes materiales a los electores; y la extensión de bienes simbólicos para conseguir lealtad y apoyo al gobierno.

\section{Representación política sustantiva y minorías indígenas en México}

En cuanto a la representación política de las minorías indígenas en México, el problema reside en el hecho de que los legisladores, según su propio discurso, suelen apegarse al principio democrático de la ciudadanía universal y, con ello, soslayan las diferencias culturales de los miembros de las sociedades actuales, es decir, de sus representados. Al respecto, Béjar (2004: 57) muestra para el caso de México "que de los 500 diputados de la LVIII Legislatura, el 63\% considera que representa a la ciudadanía en general”. Sin embargo, y de manera paradójica y violatoria del principio de la ciudadanía universal, en términos de la representación política realmente existente en México, lo que se observa es "una representación funcional que responde preponderantemente a las preferencias de los llamados grupos de interés" (Espinoza, 2004) o a la de "los intereses particulares de los partidos políticos con representación parlamentaria” (Béjar, 2006).

En México, dada la posición social que ocupan, los indígenas constituyen el grupo social más indefenso. Al no contar con representación política sustantiva no se formulan, por tanto, políticas públicas que recojan sus intereses y que, además, con la aplicación de medidas compensatorias, 
tiendan a promover esa ciudadanía universal que poseen el resto de integrantes de la misma sociedad.

En este marco, el objetivo en este estudio consistió en identificar la subjetividad política de indios mexicanos respecto de la representación política sustantiva de la que son objeto por parte de sus representantes.

\section{Método}

Se entrevistó a 46 indios mexicanos en sus lugares de origen, 25 que viven en el estado de Oaxaca (19 Zapotecas, 3 Mixtecos, 2 Mixes y 1 Mazateco) y los otros 21 en el estado de Chiapas (19 Tzotziles, 1 Tzeltal y 1 Chol)). Se diseñó una entrevista semiestructurada conformada por tres secciones: (I) Datos demográficas, (II) Datos sobre participación política electoral y (III) Entrevista sobre subjetividad política. La entrevista incluye 14 preguntas que indagan sobre la subjetividad de los indígenas sobre su representación política, y está dividida en cuatro categorías y éstas, a su vez, en varias subcategorías: 1) Política y Democracia (significado del concepto); 2) Representación Política (opinión acerca de los políticos; conocimiento sobre los representantes; conocimiento sobre las funciones de los diputados); y 3) Cuestión Indígena (autoadscripción; organización social y política de las comunidades indígenas; ciudadanía e indígenas; políticos e indígenas).

Se utilizó la técnica de Análisis de Contenido mediante una distinción categorial elaborada a partir de las propuestas de Sartori (1989) y Bobbio (en Baca, 1997), para el caso de algunas de las preguntas de las categorías 1 y 2. Para el primer autor, la democracia puede entenderse en dos dimensiones articuladas: una descriptiva, referida a su realización empírica, que puede ser evaluada en sentido positivo o negativo; y otra prescriptiva, referida a su forma ideal, evaluada sólo en sentido positivo. El segundo autor señala que la democracia puede entenderse como: 1) una técnica de gobierno o un complejo de instituciones, y 2) un conjunto de valores, aspiraciones y objetivos. Igualmente se incluye una categoría denominada Sentido Común, que incluye aquellas elaboraciones de las personas que son parte de la información que poseen, pero que tienen la característica de ser muy simples y/o de incluir tópicos comunes. Para la categoría 3, así como para algunas preguntas de las categorías 1 y 2, se categorizó a partir de las propias respuestas de los entrevistados.

\section{Resultados}

\section{Datos Demográficos Indígenas}

Del total de indígenas participantes, el 54\% son hombres y el $46 \%$ son mujeres; el 57\% tiene entre 30 y 59 años de edad. Los indígenas entrevistados en Oaxaca tienen una escolaridad más alta (un tercio de la muestra cuenta con preparatoria), en comparación con la muestra de Chiapas 
(dos terceras partes no tienen estudios o apenas concluyeron la primaria). En cuanto a la ocupación de los entrevistados, la agricultura, el comercio y el hogar son las actividades que realizan con mayor frecuencia. Por último, cerca de la mitad de los indígenas (45\%) percibe uno o menos de un salario mínimo mensual.

\section{Participación Político Electoral Indígenas Participación electoral}

Casi siete de cada diez indígenas entrevistados no votaron en las últimas elecciones (65\% total de la muestra; $80 \%$ en Oaxaca y 48\% en Chiapas).

\section{Conocimiento de las propuestas de campaña}

La mitad de la muestra señala haberse enterado de las propuestas (52\% total de la muestra). La televisión y la radio son los medios más referidos. Destaca que el internet no constituye una fuente significativa (ningún participante en Chiapas refirió este medio).

\section{Otros mecanismos de participación democrática}

Ocho de cada diez de los indígenas entrevistados no pertenecen a ninguna organización social u organización política (80\% total de la muestra; 72\% en Oaxaca y 91\% en Chiapas).

\section{Entrevista sobre Subjetividad Política}

En esta sección se ofrecen datos sobre la subjetividad política de los indígenas en relación a la representación política de la cual son objeto. Primero se presentan las cogniciones de los indígenas sobre la política y la democracia, para después señalar aspectos particulares sobre su representación política y la cuestión indígena.

\section{Política y Democracia}

\section{Significado del concepto (preguntas 2 y 3)}

Pregunta 2. Seguramente usted ha escuchado la palabra política y tiene una idea al respecto, ¿qué es lo que para usted significa la palabra política?

Tabla 1. Significados de la palabra POLÍTICA, indígenas de Oaxaca y Chiapas

\begin{tabular}{|c|c|c|c|c|c|c|c|c|c|}
\hline & \multirow{2}{*}{\multicolumn{2}{|c|}{$\begin{array}{c}\text { Sentido Común } \\
+\end{array}$}} & \multicolumn{4}{|c|}{ Descriptivo } & \multirow{2}{*}{\multicolumn{2}{|c|}{$\begin{array}{c}\text { Prescriptivo } \\
+ \\
\end{array}$}} & \multirow{3}{*}{$\begin{array}{l}\text { No } \\
\text { sabe }\end{array}$} \\
\hline & & & \multicolumn{2}{|c|}{+} & \multicolumn{2}{|c|}{-} & & & \\
\hline & 1 & 2 & 1 & 2 & 1 & 2 & 1 & 2 & \\
\hline Oaxaca & $28 \%$ & $0 \%$ & $8 \%$ & $0 \%$ & $8 \%$ & $48 \%$ & $16 \%$ & $0 \%$ & $8 \%$ \\
\hline Chiapas & $19 \%$ & $0 \%$ & $5 \%$ & $0 \%$ & $0 \%$ & $5 \%$ & $0 \%$ & $0 \%$ & $67 \%$ \\
\hline Total & $24 \%$ & $0 \%$ & $7 \%$ & $0 \%$ & $4 \%$ & $28 \%$ & $9 \%$ & $0 \%$ & $35 \%$ \\
\hline
\end{tabular}

Nota. Las respuestas de los entrevistados expresan más de una categoría, por ello el porcentaje total es mayor a 100 . 
En la Tabla 1 se observa que respecto del significado de la palabra política poco más de una tercera parte (35\%) de los indígenas entrevistados señalaron "no saber" (8\% en Oaxaca y 67\% en Chiapas). Un tzotzil señala que no existe la palabra política en su lengua. Casi otro tercio (28\%) contestó en un sentido "descriptivo negativo y valorativo" (engaño, robo, beneficio personal, promesas incumplidas): "Es para mí un engaño...nos traen y ya cuando se quedan en el poder, ya no te conozco y se van" (Zapoteco, campesino, 58 años). Otro porcentaje importante (24\%) dijo ideas de sentido común que refieren algún aspecto institucional: "La verdad desconozco. Sé que es de los partidos políticos que anden en (como se dice) campaña" (Mixteca, comerciante, 36 años).

Un 7\% de la muestra tiene ideas en un sentido descriptivo positivo, aludiendo aspectos institucionales, por ejemplo: "Involucrarse en situaciones sociales, pus para mantener un orden” (Zapoteca, empleada, 21 años). Sólo un $9 \%$ de indígenas de la muestra elaboró respuestas que implican la capacidad de formular cómo debería de ser la política o ideas prescriptivas en un sentido institucional. Aquí la respuesta de uno de los indígenas: “...La política ha ido perdiendo su fin, su fin que debe ser un beneficio para la comunidad, para toda la gente del pueblo de Oaxaca, pero no es así" (Zapoteco, mesero, 46 años).

Contrastando ambas entidades, en Oaxaca casi la mitad (48\%) de los indígenas piensan la política en un sentido descriptivo, negativo y valorativo, y sólo un indígena (5\%) en Chiapas lo hizo de esta manera. democracia?

Pregunta 3. De la misma manera, ¿qué significa para usted la palabra

Tabla 2. Significados de la palabra DEMOCRACIA, indígenas de Oaxaca y Chiapas

\begin{tabular}{|c|c|c|c|c|c|c|c|c|c|}
\hline & \multirow{2}{*}{\multicolumn{2}{|c|}{$\begin{array}{r}\begin{array}{r}\text { Sentido } \\
\text { Común }\end{array} \\
+\end{array}$}} & \multicolumn{4}{|c|}{ Descriptivo } & \multirow{2}{*}{\multicolumn{2}{|c|}{$\begin{array}{c}\text { Prescriptivo } \\
+\end{array}$}} & \multirow{3}{*}{$\begin{array}{c}\text { No } \\
\text { sabe }\end{array}$} \\
\hline & & & \multicolumn{2}{|c|}{+} & \multicolumn{2}{|c|}{ - } & & & \\
\hline & 1 & 2 & 1 & 2 & 1 & 2 & 1 & 2 & \\
\hline Oaxaca & $52 \%$ & $0 \%$ & $8 \%$ & $0 \%$ & $4 \%$ & $4 \%$ & $0 \%$ & $0 \%$ & $32 \%$ \\
\hline Chiapas & $19 \%$ & $0 \%$ & $5 \%$ & $0 \%$ & $0 \%$ & $5 \%$ & $0 \%$ & $0 \%$ & $71 \%$ \\
\hline Total & $37 \%$ & $0 \%$ & $7 \%$ & $0 \%$ & $2 \%$ & $4 \%$ & $0 \%$ & $0 \%$ & $50 \%$ \\
\hline
\end{tabular}

Nota. Las respuestas de los entrevistados expresan más de una categoría, por ello el porcentaje total es mayor a 100.

En la Tabla 2 se muestra que para la palabra democracia la mitad (50\%) de los indígenas señalaron "no saber (32\% en Oaxaca y $71 \%$ en Chiapas). Una respuesta ilustrativa: “...Ahora sí como dice el dicho, me quedo atorado porque no le he estudiado mucho de esa palabra pues...” (Mazateco, campesino, 60 años).

Un poco más de un tercio de la muestra de indígenas entrevistados (37\%) respondieron con ideas de sentido común, que refieren a la 
democracia como un sistema de gobierno, voluntad del pueblo o de la mayoría, la capacidad de elegir autoridades o el derecho al voto; o también, que la asociaban de forma simple a algún valor democrático, igualdad o libertad. Un fragmento que ejemplifica esta categoría es: “...Que un pueblo elija a su gobernante ¿no?, por medio del voto...” (Mixteca, comerciante, 36 años). Es de destacar que un indígena señaló: “el respeto a la diversidad”.

Un 7\% respondió con ideas descriptivas positivas y que refieren algún aspecto institucional; y un 4\% refirió ideas descriptivas negativas y que también refieren algún aspecto institucional. Un par de expresiones como ilustración: "Aquí es muy difícil de entender... es una palabra que existe en San Cristóbal...porque es más consciente, más humanista, que mejora la situación. La verdad no existe” (Tzotzil, campesino, 63 años); "Cuento infantil, que no existe” (Mixteco, maestro bilingüe, 38 años).

\section{Representación Política}

\section{Opinión acerca de los políticos (pregunta 4)}

Pregunta 4. Los políticos, es decir, los gobernantes y legisladores (diputados y senadores) son los encargados de tomar decisiones que afectan nuestras vidas, ¿qué es lo que usted piensa de ellos?

Tabla 3. Opiniones sobre los POLÍTICOS, indígenas de Oaxaca y Chiapas

\begin{tabular}{|c|c|c|c|c|c|c|c|c|c|}
\cline { 2 - 10 } & \multicolumn{2}{c|}{$\begin{array}{c}\text { Sentido } \\
\text { Común }\end{array}$} & \multicolumn{4}{c|}{ Descriptivo } & \multicolumn{2}{c|}{ Prescriptivo } & \multirow{2}{*}{$\begin{array}{c}\text { No } \\
\text { sabe }\end{array}$} \\
\cline { 2 - 11 } & $\mathbf{1}$ & $\mathbf{2}$ & $\mathbf{1}$ & $\mathbf{2}$ & $\mathbf{1}$ & $\mathbf{2}$ & $\mathbf{1}$ & $\mathbf{2}$ & \\
\hline Oaxaca & $0 \%$ & $0 \%$ & $4 \%$ & $0 \%$ & $4 \%$ & $\mathbf{8 0} \%$ & $8 \%$ & $\mathbf{8 \%}$ & $\mathbf{4 \%}$ \\
\hline Chiapas & $5 \%$ & $0 \%$ & $0 \%$ & $0 \%$ & $5 \%$ & $\mathbf{2 9 \%}$ & $0 \%$ & $\mathbf{5 \%}$ & $\mathbf{6 2 \%}$ \\
\hline Total & $2 \%$ & $0 \%$ & $2 \%$ & $0 \%$ & $4 \%$ & $\mathbf{5 7 \%}$ & $4 \%$ & $\mathbf{7 \%}$ & $\mathbf{3 0 \%}$ \\
\hline
\end{tabular}

Nota. Las respuestas de los entrevistados expresan más de una categoría, por ello el porcentaje total es mayor a 100.

En la Tabla 3 se aprecia que ante la pregunta ¿qué piensa de los políticos?, el 57\% del total de la muestra (80\% en Oaxaca y 29\% en Chiapas) de los indígenas ofrecen formulaciones descriptivas negativas y centradas más en aspectos axiológicos (mentirosos, corruptos, rateros, vividores de la sociedad, que ven por intereses propios, partidistas o de los poderosos). Por otro lado, 30\% de los indígenas entrevistados respondieron "no sé". Esto sucede con el 62\% de indígenas en Chiapas, mientras que en Oaxaca sólo un indígena (4\%) contestó de ese modo.

\section{Conocimiento sobre los representantes (pregunta 5)}

Pregunta 5. De manera particular, ¿usted conoce a su diputado federal y/o a su diputado local?, ¿sabe a qué partido pertenece? 
En la Tabla 4 se observa que siete de cada diez indígenas entrevistados no conocen a su diputado, y seis de cada diez no conocen el partido al que pertenecen.

Tabla 4. Conocimiento del DIPUTADO y PARTIDO de pertenencia, indígenas de Oaxaca y Chiapas

\begin{tabular}{|c|c|c|c|c|}
\hline Conoces a ... & \multicolumn{2}{|c|}{ Sí } & \multicolumn{2}{c|}{ No } \\
\hline & Oaxaca & Chiapas & Oaxaca & Chiapas \\
\hline & $28 \%$ & $33 \%$ & $72 \%$ & $67 \%$ \\
\hline tu Diputado & $32 \%$ & $30 \%$ & \multicolumn{2}{c|}{$\mathbf{7 0 \%}$} \\
\hline & $39 \%$ & $68 \%$ & $52 \%$ \\
\hline su Partido & \multicolumn{3}{|c|}{$39 \%$} & \multicolumn{3}{c|}{} \\
\hline
\end{tabular}

Conocimiento sobre las funciones de los diputados (preguntas 6, 7, 8 y 9)

Pregunta 6. Independientemente de que conozca o no a su diputado, ¿sabe cuáles son las principales responsabilidades de los diputados?

Tabla 5. Conocimiento de las RESPONSABILIDADES de los diputados, indígenas de

Oaxaca y Chiapas

\begin{tabular}{|c|c|c|c|c|c|}
\hline \multicolumn{2}{|c|}{ No sabe } & \multicolumn{2}{c|}{ Representación política } & \multicolumn{2}{c|}{ Legislar } \\
\hline Oaxaca & Chiapas & Oaxaca & Chiapas & Oaxaca & Chiapas \\
\hline $28 \%$ & $62 \%$ & $56 \%$ & $29 \%$ & $28 \%$ & $10 \%$ \\
\hline \multicolumn{2}{|c|}{$\mathbf{4 3 \%}$} & \multicolumn{2}{c|}{$20 \%$} \\
\hline
\end{tabular}

Como se muestra en la Tabla 5 , un $43 \%$ de los indígenas entrevistados señalan "no conocer" las funciones de los diputados (28\% en Oaxaca y $62 \%$ en Chiapas). Del resto, también un $43 \%$ señala como la principal función de los diputados la de "representar al pueblo" (servir a los intereses y necesidades del pueblo) y en un menor porcentaje se menciona la tarea de "legislar" (20\%). Resultan ilustrativas las siguientes respuestas: "Pues trabajar para el pueblo" (Tzotzil, agricultor, 21 años). "Velar por los intereses del pueblo" (Mixteco, profesor bilingüe, 38 años). "Legislar...ponerse de acuerdo en cosas para estar mejor acá... ¡si yo voté por él pos!" (Zapoteco, comerciante, 58 años). "Son los que llevan nuestro sentir, nuestras necesidades a la cámara para así beneficiar al pueblo" (Zapoteco, mesero, 46 años). Cabe señalar que otras funciones de los diputados no fueron mencionadas por ninguno de los entrevistados (consulta, informe de labores, rendición de cuentas y vigilancia y control de otros poderes).

Pregunta 7. Los diputados son los encargados de hacer leyes, pero en una democracia las leyes deben expresar las preferencias e intereses de la ciudadanía. En este sentido, los diputados deben consultar a sus representados. ¿A usted alguna vez su diputado le ha pedido su opinión, o ha consultado a su comunidad? 
Tabla 6. CONSULTA de los diputados a indígenas de Oaxaca y Chiapas

\begin{tabular}{|c|c|c|c|c|c|}
\hline \multicolumn{2}{|c|}{ No } & \multicolumn{2}{c|}{ Sí } & \multicolumn{2}{c|}{ No sabe } \\
\hline Oaxaca & Chiapas & Oaxaca & Chiapas & Oaxaca & Chiapas \\
\hline $84 \%$ & $76 \%$ & $8 \%$ & $14 \%$ & $8 \%$ & $10 \%$ \\
\hline \multicolumn{2}{|c|}{$11 \%$} & \multicolumn{2}{c|}{$9 \%$} \\
\hline
\end{tabular}

En la Tabla 6 se aprecia que el $80 \%$ de los indígenas entrevistados señalan nunca haber sido consultados por sus diputados (84\% en Oaxaca y $76 \%$ en Chiapas).

Pregunta 9. A cambio del voto que les damos (lo que significa que los autorizamos para tomar decisiones por nosotros), los diputados deben rendir cuentas de sus acciones, ¿usted sabe si su diputado informa sobre lo que ha hecho?

Tabla 7. INFORMAN los diputados a indígenas de Oaxaca y Chiapas

\begin{tabular}{|c|c|c|c|c|c|c|c|}
\hline \multicolumn{2}{|c|}{ No } & \multicolumn{2}{c|}{$\begin{array}{c}\text { Sí, } \\
\text { insuficientemente }\end{array}$} & \multicolumn{2}{c|}{ Sí No sabe } \\
\hline Oaxaca & Chiapas & Oaxaca & Chiapas & Oaxaca & Chiapas & Oaxaca & Chiapas \\
\hline $64 \%$ & $57 \%$ & $20 \%$ & $19 \%$ & $0 \%$ & $10 \%$ & $16 \%$ & $14 \%$ \\
\hline \multicolumn{2}{|c|}{$\mathbf{6 1 \%}$} & \multicolumn{2}{|c|}{$20 \%$} & \multicolumn{2}{c|}{$4 \%$} & \multicolumn{2}{c|}{$15 \%$} \\
\hline
\end{tabular}

En la Tabla 7 se observa que ocho de cada diez indígenas reportan que sus diputados no informan, ni rinden cuentas de sus acciones o lo hacen insuficientemente (81\%).

Pregunta 8. Los diputados deben representar a la ciudadanía y, en este sentido, recoger y defender sus intereses. ¿Usted piensa que su diputado lo representa políticamente a usted o a su comunidad?

En la Tabla 8 se muestra que siete de cada diez indígenas no se sienten representados o sólo de forma insuficiente. Resultan ilustrativas algunas frases: "Políticamente sí, pero a la comunidad no creo" (Mixteco, profesor bilingüe, 38 años). "Representan más el color de su partido que a la ciudadanía” (Zapoteco, empleado, 37 años). “Sí, así dicen ¿no?” (Tzotzil, comerciante, 36 años).

Tabla 8. Diputados REPRESENTAN POLÍTICAMENTE a indígenas de Oaxaca y Chiapas

\begin{tabular}{|c|c|c|c|c|c|c|c|}
\hline \multicolumn{2}{|c|}{ No } & \multicolumn{2}{c|}{$\begin{array}{c}\text { Sí, } \\
\text { insuficientemente }\end{array}$} & \multicolumn{2}{c|}{ Sí } & \multicolumn{2}{c|}{ No sabe } \\
\hline Oaxaca & Chiapas & Oaxaca & Chiapas & Oaxaca & Chiapas & Oaxaca & Chiapas \\
\hline $52 \%$ & $57 \%$ & $32 \%$ & $5 \%$ & $0 \%$ & $19 \%$ & $16 \%$ & $19 \%$ \\
\hline \multicolumn{2}{|c|}{$\mathbf{5 4 \%}$} & \multicolumn{2}{|c|}{$20 \%$} & \multicolumn{2}{c|}{$9 \%$} & \multicolumn{2}{c|}{$17 \%$} \\
\hline
\end{tabular}

\section{Cuestión Indígena (preguntas 1, 10, 11, 12, 13 y 14)}

\section{Autoadscripción, condición de etnia y habla indígena (pregunta 1)}

Pregunta 1 . ¿Usted se reconoce como indígena?, ¿es usted -grupo étnico-?; ¿habla usted -lengua-?; ¿qué es lo que distingue a su grupo étnico o comunidad respecto de otros grupos? 
Tabla 9. GRUPO ÉTNICO, indígenas de Oaxaca y Chiapas

\begin{tabular}{|c|c|}
\hline Oaxaca & Chiapas \\
\hline $\begin{array}{c}\text { Zapoteco } \\
\text { (19 participantes) }\end{array}$ & Tzotzil \\
(19 participantes) \\
\hline Mixteco & Tzeltal \\
(3 participantes) & (1 participante) \\
\hline Mixe & Chol \\
(2 participantes) & (1 participante) \\
\hline Mazateco & \\
\hline (1 participante) & 21 participantes \\
\hline
\end{tabular}

En la Tabla 9 se observa el grupo étnico de los indígenas entrevistados bajo el criterio de autoadscripción. Cabe destacar que las etnias participantes pertenecen a las más abundantes en Oaxaca y Chiapa, según datos del Instituto Nacional de Estadística y Geografía (INEGI, 2011).

Tabla 10. Hablantes de LENGUA INDÍGENA, Oaxaca y Chiapas

\begin{tabular}{|c|c|c|c|}
\hline \multicolumn{2}{|c|}{ Hablantes } & \multicolumn{2}{|c|}{ No hablantes } \\
\hline Oaxaca & Chiapas & Oaxaca & Chiapas \\
\hline $68 \%$ & $100 \%$ & $32 \%$ & $0 \%$ \\
\hline \multicolumn{2}{|c|}{$83 \%$} & \multicolumn{2}{|c|}{$17 \%$} \\
\hline
\end{tabular}

En la Tabla 10 se observa que gran parte de la muestra son hablantes de lenguas indígenas (83\%). En Chiapas todos los indígenas entrevistados hablan una lengua mexicana. En Oaxaca ocho entrevistados (32\%) no son hablantes; sin embargo, sí se autoadscribieron como indígenas. Cabe señalar que las lenguas de los participantes son también las más frecuentes en Oaxaca y Chiapas, según cifras del Instituto Nacional de Estadística y Geografía (INEGI, 2011).

Tabla 11. ¿Qué es lo que distingue a su grupo étnico o comunidad respecto de otros grupos?

\begin{tabular}{|c|c|c|c|c|c|c|c|}
\hline \multicolumn{2}{|c|}{ Lengua } & \multicolumn{2}{c|}{ Usos y costumbres } & \multicolumn{2}{c|}{$\begin{array}{c}\text { Formas de } \\
\text { organización }\end{array}$} & \multicolumn{2}{c|}{ Raza y Religión } \\
\hline Oaxaca & Chiapas & Oaxaca & Chiapas & Oaxaca & Chiapas & Oaxaca & Chiapas \\
\hline $60 \%$ & $43 \%$ & $56 \%$ & $48 \%$ & $16 \%$ & $10 \%$ & $0 \%$ & $5 \%$ \\
\hline \multicolumn{2}{|c|}{$5 \mathbf{5 2 \%}$} & \multicolumn{2}{|c|}{$\mathbf{5 2 \%}$} & \multicolumn{2}{c|}{$13 \%$} & \multicolumn{2}{c|}{$2 \%$} \\
\hline
\end{tabular}

Nota. Las respuestas de los entrevistados expresan más de una categoría, por ello el porcentaje total es mayor a 100.

En la Tabla 11 se muestra que los indígenas entrevistados señalan a la lengua (52\%), los usos y costumbres (cultura, tradiciones, fiestas, vestimenta, gastronomía) (52\%), las formas de organización (política, social y territorial) (13\%) y la raza y religión (2\%), como las características que distinguen a su grupo étnico o comunidad de otros grupos. Revisemos un discurso: "Las mujeres usan enredos...y usan sus camisas floreadas...El hombre usa huaraches de pata de gallo...usan calzón de manta...utilizan siempre su jorongo...su sombrero es de panza de burro...Hay zapotecas en 
la Sierra Sur; hay zapotecas del Valle y hay zapotecas en la Sierra Norte...entonces, cada región tiene una forma parecida, pero no idéntica de organizarse políticamente...Mañana se celebra un santo...hay una persona que sabe cómo se acomoda la imagen, cuántas velas debe llevar, cuántas jarras de flores...” (Zapoteco, Lic. en Ciencias Sociales y campesino, 57 años).

\section{Organización social y política de las comunidades indígenas (pregunta 10)}

Pregunta 10. En su comunidad existen ciertas formas de organización social y política, ¿cómo eligen a sus autoridades?, ¿cómo es y cómo funciona la estructura de autoridad de su comunidad?, ¿existe relación con la estructura del gobierno nacional y del estado?, ¿cómo es ésta?

Como se observa en la Tabla 12, tres de cada diez indígenas señalan que ya no existen en sus comunidades formas especiales de organización social y política, debido a que actualmente se rigen por las directrices de los partidos políticos. "En la actualidad han entrado los partidos políticos a echar abajo toda esa organización tan bonita que teníamos...Ahorita ya se nombre un cabildo por medio de partidos políticos como en la ciudad...Ya lo de usos y costumbres lo dejaron atrás, que era la forma original en que se organizaban los zapotecas” (Zapoteco, campesino, 57 años).

Tabla 12. ¿En su comunidad existen ciertas formas de organización social y política?

\begin{tabular}{|c|c|c|c|c|c|}
\hline \multicolumn{2}{|c|}{ Sí } & \multicolumn{2}{c|}{ No } & \multicolumn{2}{c|}{ No sabe } \\
\hline Oaxaca & Chiapas & Oaxaca & Chiapas & Oaxaca & Chiapas \\
\hline $56 \%$ & $43 \%$ & $36 \%$ & $19 \%$ & $8 \%$ & $29 \%$ \\
\hline \multicolumn{2}{|c|}{$\mathbf{5 0 \%}$} & \multicolumn{2}{|c|}{$22 \%$} \\
\hline
\end{tabular}

No obstante, la mitad de los entrevistados refieren que sí existen. Cuentan que para tomar decisiones la comunidad se reúne en asambleas, donde se vota a mano alzada. La asistencia es obligatoria y faltar a ella es motivo de multa. Los cargos públicos son únicamente para la gente originaria y son postulados y electos por la comunidad. Así el pueblo sabe del funcionario y el funcionario conoce las verdaderas necesidades de la comunidad. En algunas comunidades aún el consejo de ancianos es la máxima autoridad. Comentan también que el castigo más severo para quien comete una falta es la expulsión de la comunidad. Cabe destacar que los usos y costumbres, en algunas comunidades, establecen que la mujer no puede votar, ni ser electa a un cargo público.

Algunos indígenas narran que la relación entre la política nacional y las formas internas de organización (a veces de usos y costumbres) es distante o a conveniencia, otros más la acusan de conflictiva. Cabe comentar que en el momento en el que se hizo el trabajo de campo, en uno de los poblados tenían tomado el Ayuntamiento Municipal, acción que implicaba el 
desconocimiento del cabildo (la máxima autoridad del pueblo) y al mismo tiempo la política partidista. Como señal de inconformidad se impidió, exitosamente, el levantamiento de casillas de las últimas elecciones. Cabe resaltar que el cabildo desconocido era miembro de la comunidad indígena. Antes conocido por ser humilde y servicial, y que a partir de tomar el poder se le vio como lejano, mentiroso y corrupto. Al respeto es valioso el siguiente fragmento:

"(Los partidos políticos) Hace dieciocho años...vinieron a dividirnos; lo único que se logró es que vinieran a dividir al pueblo y estamos en esa problemática ahorita... Llegó un presidente déspota y se sintió como el rey del mundo, porque veía a sus paisanos como Dios mira a los conejos chiquitos y orejones...nos trataba con la punta del pie. En dos ocasiones tomamos la Cámara de Diputados... lo que pedimos es la desaparición de poderes del cabildo municipal...lo cual han hecho caso omiso de todas las peticiones que nosotros hemos llevado...El cinco de octubre (2014) que desconocimos al cabildo, el pueblo se reunió y nombró a una comisión representativa... (El siete de noviembre de 2014) se nombra un consejo municipal: el presidente del consejo, el síndico del consejo y sus suplentes; el regidor de la hacienda, el regidor de educación, el regidor de policía... Nosotros no estamos cobrando ninguna dieta, ni nada. Estamos cumpliendo un servicio que el pueblo nos mandó y que hacemos hasta donde es posible cumplir con todos los servicios; por ejemplo, darles atención a las escuelas, a la casa de cultura, a cualquier institución..." (Zapoteco, regidor de educación, 57 años).

\section{Ciudadanía e Indígenas (preguntas 11, 12 y 14)}

Pregunta 11. En el México de hoy, ¿qué significa ser indígena?, ¿cómo siente usted que lo tratan las personas que no son indígenas?

Tabla 13. En el México de hoy, ¿qué significa ser indígena?

\begin{tabular}{|c|c|c|c|c|c|}
\hline \multicolumn{2}{|c|}{ Valoraciones positivas } & \multicolumn{2}{c|}{ Valoraciones negativas } & \multicolumn{2}{c|}{ No sabe } \\
\hline Oaxaca & Chiapas & Oaxaca & Chiapas & Oaxaca & Chiapas \\
\hline $68 \%$ & $14 \%$ & $32 \%$ & $29 \%$ & $8 \%$ & $62 \%$ \\
\hline \multicolumn{2}{|c|}{$\mathbf{3 0 \%}$} & \multicolumn{2}{c|}{$33 \%$} \\
\hline
\end{tabular}

Nota. Las respuestas de los entrevistados expresan más de una categoría, por ello el porcentaje total es mayor a 100.

En la Tabla 13 se observa que casi en la misma proporción los entrevistados brindaron valoraciones tanto positivas como negativas a la pregunta ¿qué significa ser indígena? Las valoraciones positivas contienen respuestas como: orgullo, valioso, humildad, alegría, ventaja. Algunos ejemplos son: "Pues un orgullo... son pocas las personas que todavía conservan sus costumbres, sus tradiciones" (Zapoteca, empleada, 19 años). "Ay, muy valioso... la gente ahorita se avergüenza de ser indígena, hasta es 
como una ofensa de otros...te dicen ¡ay indio!, ¡indígena!... cuando es todo lo contrario...Sí, a mucha honra, no es una ofensa” (Zapoteca, empleada, 21 años). "Es una ventaja, podemos platicar sin que usted se entere y no sabe lo que estamos diciendo...hasta hay gringos que dicen oye enséñame a hablar zapoteco ¿no? y así vamos cotorreando” (Zapoteco, albañil, 27 años).

Las valoraciones negativas contienen respuestas como: olvido y exclusión, racismo, menosprecio. Algunas respuestas ilustrativas: "Nos tienen olvidados, nos tienen pisoteados” (Mixteco, empleado, 55 años). "Los indígenas vienen con huaraches, a veces vienen unos con parche $\mathrm{y}$ claramente la gente se hace a un ladito, porque lo ven mal, pero somos humanos; así podemos vestir” (Zapoteca, campesino, 58 años). "Significa ser como ciudadano de último nivel” (Zapoteco, campesino, 62 años).

Tabla 14. ¿Cómo siente que lo tratan las personas que no son indígenas?

\begin{tabular}{|c|c|c|c|c|c|c|c|}
\hline \multicolumn{4}{|c|}{ Valoraciones negativas } & \multirow{2}{*}{\multicolumn{2}{|c|}{$\begin{array}{c}\begin{array}{c}\text { Valoraciones } \\
\text { positivas }\end{array} \\
\text { Bien } \\
\end{array}$}} & \multirow{2}{*}{\multicolumn{2}{|c|}{$\begin{array}{l}\text { No sabe/ } \\
\text { No contestó }\end{array}$}} \\
\hline \multicolumn{2}{|c|}{ Discriminación } & \multicolumn{2}{|c|}{ Exclusión } & & & & \\
\hline Oахаса & Chiapas & Oaxaca & Chiapas & Oахаса & Chiapas & Oахаса & Chiapas \\
\hline $80 \%$ & $48 \%$ & $16 \%$ & $10 \%$ & $12 \%$ & $10 \%$ & $16 \%$ & $48 \%$ \\
\hline \multicolumn{2}{|c|}{$65 \%$} & \multirow{2}{*}{\multicolumn{2}{|c|}{$13 \%$}} & \multicolumn{2}{|c|}{$11 \%$} & \multicolumn{2}{|c|}{$30 \%$} \\
\hline \multicolumn{2}{|c|}{$78 \%$} & & & \multicolumn{2}{|c|}{$11 \%$} & \multicolumn{2}{|c|}{$30 \%$} \\
\hline
\end{tabular}

Nota. Las respuestas de los entrevistados expresan más de una categoría, por ello el porcentaje total es mayor a 100 .

En la Tabla 14 destaca que ocho de diez indígenas refieren que las personas no indígenas los tratan mal. Principalmente discriminándolos, también excluyéndolos. Sólo un indígena de cada diez dice que lo tratan bien. La discriminación se ilustra en los siguientes comentarios: "Mucho racismo, mucha humillación...me gana la emoción...se vive en la carne propia (llora)" (Tzotzil, campesino, 63 años). "Generalmente despectivo... desde el primer momento en que vamos a una oficina y nos ven entrar con huaraches; inmediatamente mandan a trapear el lugar donde pasamos, porque no se quieren contagiar a lo mejor de nosotros, del polvo que traemos en los huaraches" (Zapoteco, campesino, 57 años). La exclusión se ejemplifica con el comentario: "No nos toman en cuenta" (Tzotzil, agricultor, 43 años). indígenas?

Pregunta 12. ¿Cómo deben tratarlos las personas que no son

Tabla 15. ¿Cómo deben tratarlos las personas que no son indígenas?

\begin{tabular}{|c|c|c|c|c|c|c|c|c|c|}
\hline \multicolumn{8}{|c|}{ Valoraciones positivas/prescriptivas } & \multirow{2}{*}{\multicolumn{2}{|c|}{$\begin{array}{c}\text { No sabe/ } \\
\text { No contestó }\end{array}$}} \\
\hline \multicolumn{2}{|c|}{ Respeto } & \multicolumn{2}{|c|}{ Igualdad } & \multicolumn{2}{|c|}{ Fraternidad } & \multicolumn{2}{|c|}{ Honestidad } & & \\
\hline 1 & 2 & 1 & 2 & 1 & 2 & 1 & 2 & 1 & 2 \\
\hline $44 \%$ & $24 \%$ & $44 \%$ & $19 \%$ & $8 \%$ & $0 \%$ & $4 \%$ & $0 \%$ & $24 \%$ & $57 \%$ \\
\hline \multicolumn{2}{|c|}{$35 \%$} & \multicolumn{2}{|c|}{$33 \%$} & \multicolumn{2}{|c|}{$4 \%$} & \multicolumn{2}{|c|}{$2 \%$} & \multicolumn{2}{|c|}{$38 \%$} \\
\hline
\end{tabular}

Nota. Las respuestas de los entrevistados expresan más de una categoría, por ello el porcentaje total es mayor a 100. 
En la Tabla 15 se muestra cómo creen los indígenas que deben ser tratados por los no indígenas: con respeto, igualdad, fraternidad y honestidad. Algunas respuestas alusivas son: "Igual que a todos... una persona merece respeto" (Zapoteca, empleada, 21 años). "Hay que tratarnos como hermanos, parejo..." (Zapoteco, albañil, 27 años). "Ser amables, ser sinceros... que no nos engañen” (Zapoteco, chofer, 57 años). Por otra parte, destaca que cuatro de cada diez indígenas no saben qué contestar, siendo mayor este porcentaje en Chiapas.

Pregunta 14. Pensando en la diversidad cultural de este país... ¿qué tenemos que hacer los ciudadanos para que podamos convivir todos en paz y sin excluir, ni discriminar, a ningún grupo?

En la Tabla 16 se aprecia que los indígenas piensan que, para poder convivir en paz sin excluir, ni discriminar a ningún grupo, principalmente se debe fomentar y actuar conforme a diversos valores democráticos (igualdad, respeto, justicia); también señalan la necesidad de incluir a los indígenas (conocer las comunidades, convivir con los indígenas, ser fraterno). En menor proporción se señala la necesidad de educar y concientizar a la población y optar por una lucha social pacífica. No obstante, lo más sobresaliente es que alrededor de la mitad de los indígenas entrevistados no supo que contestar, no encontró respuesta.

Tabla 16. ¿Qué tenemos que hacer los ciudadanos para que podamos convivir todos en paz y sin excluir ni discriminar a ningún grupo?

\begin{tabular}{|c|c|c|c|c|c|c|c|c|c|}
\hline \multicolumn{8}{|c|}{ Valoraciones positivas/ prescriptivas } & \multirow{2}{*}{\multicolumn{2}{|c|}{$\begin{array}{c}\text { No sabe/ } \\
\text { No contestó }\end{array}$}} \\
\hline \multicolumn{2}{|c|}{ Valores } & \multicolumn{2}{|c|}{ Inclusión } & \multicolumn{2}{|c|}{ Educación } & \multicolumn{2}{|c|}{ Lucha social } & & \\
\hline 1 & 2 & 1 & 2 & 1 & 2 & 1 & 2 & 1 & 2 \\
\hline $20 \%$ & $29 \%$ & $24 \%$ & $14 \%$ & $12 \%$ & $0 \%$ & $4 \%$ & $0 \%$ & $48 \%$ & $67 \%$ \\
\hline \multicolumn{2}{|c|}{$24 \%$} & \multicolumn{2}{|c|}{$20 \%$} & & $7 \%$ & \multicolumn{2}{|c|}{$2 \%$} & \multicolumn{2}{|c|}{$56 \%$} \\
\hline
\end{tabular}

1 = Oaxaca; 2 = Chiapas

Nota. Las respuestas de los entrevistados expresan más de una categoría, por ello el porcentaje total es mayor a 100.

\section{Políticos e Indígenas (pregunta 13)}

Pregunta 13. ¿Cómo son tratados ustedes por los políticos?, ¿cómo piensa usted que los deben tratar?

Tabla 17. ¿Cómo son tratados por los políticos?

\begin{tabular}{|c|c|c|c|c|c|c|c|c|c|}
\hline \multicolumn{6}{|c|}{ Valoraciones negativas/descriptivas } & \multirow{2}{*}{\multicolumn{2}{|c|}{$\begin{array}{c}\begin{array}{c}\text { Valoración } \\
\text { positiva/ real }\end{array} \\
\text { Bien }\end{array}$}} & \multicolumn{2}{|c|}{$\begin{array}{c}\text { No sabe/ } \\
\text { No contestó }\end{array}$} \\
\hline \multicolumn{2}{|c|}{ A conveniencia } & \multicolumn{2}{|c|}{ Discriminación } & \multicolumn{2}{|c|}{$\begin{array}{c}\text { Olvido/ } \\
\text { Exclusión }\end{array}$} & & & & \\
\hline 1 & 2 & 1 & 2 & 1 & 2 & 1 & 2 & 1 & 2 \\
\hline $64 \%$ & $14 \%$ & $32 \%$ & $29 \%$ & $12 \%$ & $19 \%$ & $8 \%$ & $10 \%$ & $8 \%$ & $33 \%$ \\
\hline \multicolumn{2}{|c|}{$41 \%$} & \multicolumn{2}{|c|}{$30 \%$} & \multicolumn{2}{|c|}{$15 \%$} & \multicolumn{2}{|c|}{$9 \%$} & \multicolumn{2}{|c|}{$19 \%$} \\
\hline \multicolumn{6}{|c|}{$86 \%$} & \multicolumn{2}{|c|}{$9 \%$} & \multicolumn{2}{|c|}{$19 \%$} \\
\hline
\end{tabular}

$$
1 \text { = Oaxaca; } 2 \text { = Chiapas }
$$

Nota. Las respuestas de los entrevistados expresan más de una categoría, por ello el porcentaje total es mayor a 100 . 
En la Tabla 17 se muestra que casi nueve de cada diez indígenas consideran que son tratados mal por los políticos, ya sea porque sienten ser tratados por ellos a conveniencia e "hipócritamente", dicen sufrir discriminación a causa de su origen o etnia, o se sienten olvidados y excluidos. Resultan ilustrativas las siguientes opiniones: "Pues así, usados nomás” (Tzotzil, artesana, 33 años). “...Somos más rechazados que los que no son indígenas" (Chol, campesino, 62 años). "Solamente son tomados en cuenta (los indígenas) cuando están haciendo sus campañas. Ahí sí visitan las localidades y ofrecen promesas ¿no? Muchas cosas que al final nunca cumplen. Y cuando ya están al frente del cargo no se acuerdan, no visitan...Son olvidados” (Mixe, comerciante, 23 años).

Hay que señalar que de toda la muestra sólo cuatro indígenas señalaron ser tratados bien por los políticos. Además, dos de cada diez indígenas no contestaron a la pregunta, siendo mayor el porcentaje en Chipas (siete indígenas).

Tabla 18. ¿Cómo piensa que debería ser tratado por los políticos?

\begin{tabular}{|c|c|c|c|c|c|c|c|c|c|}
\hline \multicolumn{8}{|c|}{ Valoraciones positivas/ prescriptivas } & \multirow{2}{*}{\multicolumn{2}{|c|}{$\begin{array}{c}\text { No sabe/ } \\
\text { No contestó }\end{array}$}} \\
\hline \multicolumn{2}{|c|}{ Responsabilidad } & \multicolumn{2}{|c|}{ Respeto } & \multicolumn{2}{|c|}{ Igualdad } & \multicolumn{2}{|c|}{ Sinceridad } & & \\
\hline 1 & 2 & 1 & 2 & 1 & 2 & 1 & 2 & 1 & 2 \\
\hline $44 \%$ & $14 \%$ & $16 \%$ & $19 \%$ & $12 \%$ & $19 \%$ & $4 \%$ & $0 \%$ & $48 \%$ & $57 \%$ \\
\hline \multicolumn{2}{|c|}{$30 \%$} & \multicolumn{2}{|c|}{$17 \%$} & \multicolumn{2}{|c|}{$15 \%$} & \multicolumn{2}{|c|}{$2 \%$} & \multicolumn{2}{|c|}{$52 \%$} \\
\hline
\end{tabular}

1 = Oaxaca; 2 = Chiapas

Nota. Las respuestas de los entrevistados expresan más de una categoría, por ello el porcentaje total es mayor a 100.

En la Tabla 18 se aprecia que los indígenas piensan que deberían ser tratados por los políticos con responsabilidad, respeto, igualdad y sinceridad. La mitad de indígenas de la muestra no contestó a esta pregunta o dijo no saber (52\%). Algunos fragmentos ilustrativos: "No más con respeto ¿no? ...Y cumpliendo lo que ellos prometen” (Zapoteca, maestra de primaria, 38 años). “...Queremos que nos traten igual como no indígenas” (Chol, campesino, 62 años). "Que sean sinceros...que no nos vengan a estafar nada más" (Zapoteco, chofer, 57 años).

Pregunta 14. Pensando en la diversidad cultural de este país... En particular, ¿qué tendrían que hacer el gobierno y los diputados?

Tabla 19. Pensando en la diversidad cultural ¿Qué tendrían que hacer el gobierno y los diputados?

\begin{tabular}{|c|c|c|c|c|c|c|c|c|c|}
\hline \multicolumn{8}{|c|}{ Valoraciones positivas/prescriptivas } & \multirow{2}{*}{\multicolumn{2}{|c|}{$\begin{array}{c}\text { No sabe/ } \\
\text { No contestó }\end{array}$}} \\
\hline \multicolumn{2}{|c|}{ Responsabilidad } & \multicolumn{2}{|c|}{ Respeto } & \multicolumn{2}{|c|}{$\begin{array}{c}\text { Inclusión/ } \\
\text { Igualdad }\end{array}$} & \multicolumn{2}{|c|}{$\begin{array}{c}\text { Discriminación } \\
\text { Positiva }\end{array}$} & & \\
\hline 1 & 2 & 1 & 2 & 1 & 2 & 1 & 2 & 1 & 2 \\
\hline $32 \%$ & $19 \%$ & $24 \%$ & $29 \%$ & $8 \%$ & $14 \%$ & $12 \%$ & $5 \%$ & $32 \%$ & $57 \%$ \\
\hline \multicolumn{2}{|c|}{$26 \%$} & \multicolumn{2}{|c|}{$26 \%$} & \multicolumn{2}{|c|}{$11 \%$} & \multicolumn{2}{|c|}{$9 \%$} & \multicolumn{2}{|c|}{$43 \%$} \\
\hline
\end{tabular}

Nota. Las respuestas de los entrevistados expresan más de una categoría, por ello el porcentaje total es mayor a 100. 
En la Tabla 19 se puede observar que los indígenas consideran que ante el reto que implica la diversidad cultural, el gobierno tendría que actuar con responsabilidad y respeto, favorecer la inclusión y tomar medidas políticas compensatorias para los indígenas. Destaca que el $43 \%$ de los indígenas entrevistados dijeron "no saber"; es decir, no encontraron posibles soluciones. Algunos fragmentos ilustrativos: "El respeto entre todos..." (Tzotzil, ama de casa, 36 años). "Tratarnos por igual a todos, sin discriminar a nadie” (Tzotzil, artesana, 33 años). “Deberían ser un poco más considerados [con los indígenas] porque tienen más carencias; entonces, ahí deben de enfocar, en los pueblos indígenas” (Zapoteca, empleada, 21 años).

\section{Discusión}

En las democracias liberales, las elecciones son, efectivamente, un genuino instrumento de la democracia (Powell, 2000). Sin embargo, son sólo un instrumento electivo. Los problemas emergen cuando consideramos el comportamiento político de los funcionarios y representantes populares a la hora de gobernar. Problema que se agrava aún más en aquellos países que, como México, están lejos de consolidar su democracia (Rocha, 2012).

Las elecciones por sí mismas no garantizan que aquéllos que resultaron ganadores efectivamente atiendan los intereses de quienes los eligieron. Entonces, el asunto estriba en cómo asegurar institucionalmente que se construya un vínculo más estrecho entre los representantes y la ciudadanía, en el marco de la relativa independencia con la que cuentan los representantes para actuar y tomar decisiones. En la literatura especializada la cuestión se está enfocando en la consideración de comportamientos responsivos por parte de los representantes. Sin embargo, la pregunta evidente -pero no por ello menos compleja- es: ¿cuáles son aquellos comportamientos responsivos que debe expresar un representante popular?

La respuesta apunta sin duda a la consideración de aquellos comportamientos que beneficien a los representados. Pero en el marco de las sociedades plurales actuales, parece que tenemos más problemas que soluciones. En efecto, las paradojas de la democracia representativa parece que no tiene vías de solución, por lo menos en sociedades que si bien son democráticas presentan igualmente una enorme desigualdad social y económica entre sus miembros y que, como consecuencia, limitan el acceso a los espacios propiamente políticos a la mayoría de la población. Al respecto, podría intentarse avanzar mediante la búsqueda de mecanismos institucionales que promuevan una mayor participación política por parte de la ciudadanía en los asuntos que les conciernen y que afectan sus vidas.

El quid es cómo lograrlo cuando la calidad de la ciudadanía es aún muy pobre. Esta consideración no es una mera atribución a los ciudadanos, sino más bien habría que leerla como la correspondencia de su cultura y subjetividad 
política con las formas institucionales de hacer política. Así, respecto de los indígenas como ciudadanos, los resultados ratifican lo que se ha encontrado en anteriores estudios:

Que los sujetos piensan y definen la política, la democracia y las instituciones mediante elaboraciones que se distinguen más por su simplicidad que por la crítica y la imaginación. Su subjetividad política está permeada por informaciones de sentido común; responde más a la dimensión descriptiva, pues refiere los hechos empíricos de la vida política del país mediante una valoración altamente negativa, y se centra más en los valores, los propósito, las aspiraciones, que en el plano del entramado institucional y las técnicas de gobierno; igualmente, se distingue por su incapacidad para formular pensamientos más o menos elaborados, que vayan más allá de las generalizaciones, las abstracciones y los lugares comunes, y que perfilen, en un sentido prescriptivo, formas ideales sobre la política, la democracia y el funcionamiento de las instituciones para hacerlas realidad. Para decirlo sucintamente, su subjetividad política se corresponde con la realidad del país: la antipolítica y la ausencia de democracia. (Rocha, 2005b)

Específicamente en cuanto a la representación política de las minorías indígenas, es preciso avanzar tanto conceptual como institucionalmente. En un sentido teórico, es necesario resolver las contradicciones inherentes a la concepción liberal de la democracia respecto de su articulación con la pluralidad cultural, étnica y lingüística realmente existentes. Lograr dicha articulación es uno de los mayores desafíos del pensamiento democrático moderno. Por otro lado, el diseño institucional que articule precisamente la igualdad universal de los ciudadanos con las diferencias culturales y étnicas que les son inherentes, es hoy uno de los mayores reclamos. En la perspectiva aquí presentada, la consideración de diversos factores que se ubican en los planos institucional, subjetivo y cultural, puede ayudar a tales propósitos.

En cuanto a los indios es importante subrayar que ellos expresan no sólo el olvido del que han sido objeto por parte de los representantes, sino también el hecho de que la política nacional les resulta totalmente ajena. En cuanto a la reciprocidad y empatía de los diputados hacia los ciudadanos e indios, es posible afirmar que los comportamientos de los representantes que pudieran involucrar estas nociones, están simplemente ausentes. En ese sentido, en México los indios aún no son ciudadanos de la república.

Finalmente, el propósito ulterior de esta investigación es contribuir al diseño de mecanismos institucionales que consideren tanto los factores 
culturales como la dimensión subjetiva de la ciudadanía y los representantes, para hacer realidad la definición parsimoniosa de Lauermann (2014: 4) acerca de la representación política: “es una relación interactiva construida sobre el consentimiento, la responsividad y la rendición de cuentas”.

\section{References:}

1. Abal, J. (2004). La muerte y la resurrección de la representación política. México: Fondo de Cultura Económica.

2. Baca, L. (1997). Diálogo y democracia. Cuadernos de Divulgación de la Cultura Democrática No. 13. México: Instituto Federal Electoral.

3. Béjar, L. (2004). La representación política en México: El papel de los partidos y de los grupos parlamentarios en la LVIII Legislatura. En L. Béjar y G. Waldman (Coords.), La representación parlamentaria en México (pp. 47-76). México: UNAM y Gernika.

4. Béjar, L. (2006). Los partidos en el Congreso de la Unión. La representación parlamentaria después de la alternancia. México: UNAM y Gernika.

5. Espinoza, R. (2004). Representación de intereses y representación política en México. En L. Béjar y G. Waldman (Coords.), La representación parlamentaria en México (pp. 31-46). México: UNAM y Gernika.

6. Eulan, H. \& Karps, P. (1977). The puzzle of representation: Specifying components of responsiveness. Legislative Studies Quarterly, 2(3), 233-254.

7. Gargarella, R. (1997). Crisis de la representación política. México: Distribuciones Fontamara.

8. Instituto Nacional de Geografía y Estadística [INEGI] (2011). XIII Censo General de Población y Vivienda 2010. Recuperado de http://goo.gl/e1Yxl

9. Lauermann, R. (2014). Constituent perceptions of political representation. How citizens evaluate their representatives. New York: Palgrave Mcmillan.

10. Lindaman, K. (Ed.) (2011). Direct democracy. The struggle for democratic responsiveness and representation. New York: International Debate Education Association.

11. Manin, B., Przeworski, A. \& Stokes, S. (1999). Elections and representation. In A. Przeworski, S. Stokes \& B. Manin (Eds.), Democracy, accountability and representation (pp. 29-54). Cambridge: Cambridge University Press.

12. Morlino, L. (2007). Calidad de la democracia: Notas para su discusión. En C. Cansino e I. Covarrubias (Coords.), Por una 
democracia de calidad (pp. 27-53). México: Centro de Estudios de Política Comparada y Educación y Cultura.

13. O’Donnell, G. (2000). Further thoughts on horizontal accountability. Conference on Institutions, accountability and democratic gobernance in Latin America. Notre Dame: Kellogg Institute for International Studies.

14. Pitkin, H. (1985). El concepto de representación. Madrid: Centro de Estudios Constitucionales.

15. Powell, B. (2000). Elections as instruments of democracy. New Haven, CT: Yale University Press.

16. Przeworski, A. (1998). Democracia y representación. Revista del CLAD Reforma y Democracia, 10, 7-31.

17. Rocha, R. (2005a). Representación política y gobierno: Mecanismos institucionales para un gobierno democrático. Psicologia Política, 5(9), 33-46.

18. Rocha, R. (2005b). La subjetividad política de los mexicanos y la construcción del comportamiento democrático. En O. Manjarrez, H. Oudhof y J. L. Gama (Coords.), Psicología social y cultura política (pp. 73-102). México: Universidad Autónoma del Estado de México.

19. Rocha, R. (2012). Transición a la democracia en México. Política, instituciones y órganos de administración electoral 1990-2002. Alemania: Editorial Académica Española.

20. Rocha, R. (2016). Institutions, subjectivity and culture in Mexican indigenous minorities political representation. In D. S. Guimarães (Ed.), Amerindian paths. Guiding dialogues with psychology (pp. 87105). Advances in Cultural Psychology. Charlotte, NC: United States of America: Information Age Publishing, EUA.

21. Sartori, G. (1989). Teoría de la Democracia. Tomo 1. El debate contemporáneo. México: Alianza Editorial Mexicana. 